better." He is still, however, unable to put out his tongue, though he opens his mouth immediately when told to do so.

9th.-Passed a bad night; very restless, and suffering much from dyspncea; but the improvement in the mental condition continues; he is free from pain in the head, and says he shall get better. Pulse stronger and fuller, 78. Still unable to put out his tongue; deglutition perfect. Scalp wound nearly healed. Ordered compound spirits of sulphuric ether, thirty minims every four hours, if necessary.

10th. --Better, but still does not answer readily unless the word is suggested to him. When asked "How are you ?" he mumbled something indistinctly; but when asked "Are you better?" he answered "Better," and then voluntarily followed up the response by saying "I've more reason." Still he does not always appear to comprehend what is said. On telling him, for instance, to put out his tongue, he made no effort to do so, though it was repeated three times; but if the questioner put out his own tongue, the patient immediately opened his mouth and tried to do the same, though without success. $\mathrm{He}$ had a very good night.

12th.-Decidedly better. When asked "How are you?" he replied "Very queer;" but is now able to put out his tongue. Pulse 84, with power. His cough is now the principal ailment.

23rd. - Convalescent, and about; there having been no relapse in the head symptoms since last note. He suffers only from the chronic chest disease.

29th.-Discharged.

\section{ST. GEORGE'S HOSPITAL}

A CASE OF SOFTENING OF THE BRAIN, WITH APHASIA. (Under the care of Dr. OGLE.)

THe patient whose case is detailed below, from notes kindly supplied by Dr. Reginald Thompson, medical registrar, used to walk about the ward in a restless and vacant manner for several days after his admission, during which time we saw him more than once. His power of voluntary movements, taken in connexion with the extensive softening which was discovered after death, is an interesting point. He presented a good example of atactic aphasia, accompanied by amnemonia, of which a number of instances are given in Dr. Ogle's excellent paper on "Aphasia and Agraphia" in the lately published volume of "St. George's Hospital Reports."

Charles $\mathrm{H}-$, aged thirty, was admitted on the 7th of October last. He was a groom in the Chantilly stables, and had been sent over from France the day before his admission into the hospital. No history was obtained, and he was incapable of giving any account of himself. He could say "yes" and "no," and one or two short French words; but generally he talked gibberish, and answered questions quite unintelligibly. He could not give his name; and would not, or could not, write. He could not protrude his tongue; he could walk well, and fed himself properly with both hands; looked melancholy and hopeless. On close examination, there seemed to be some paralysis of the right side of the face, which was a little drawn, and not so mobile as the left; pupils large. At the apex of the heart a very soft sound was heard accom panying the first sound. He was ordered calomel and senna, and two drachms of the solution of bichloride of mercury, twice a day. On the 15th he was not so well, and was troublesome and fidgety luring the night. On the l6th he had two fits, in which the left side of the face and the right arm and leg were convulsed. The fits were very transient. He got noisier at night, and was reported to swear a good deal. On the 17th he had another fit; pupils equally large and much dilated. He had a succession of fits throughout the night of the 18th. From this time he became comatose, and died at noon on the 20th.

The following notes of the necropsy were made by Mr. Thos. Pick:- The body was in good condition. The whole of the middle lobe of the left side of the brain was more or less softened, the softening being greatest in the centre, but reaching the surface of the brain along the margin of the horizontal fissure of Sylvius in the temporo-sphenoid lobe. In the centre of the middle lobe the softening extended as high as a level with the upper surface of the corpus callosum ; in front it extended as far forwards, possibly a little in front of the fissure of Rolando. The ventricles were full of clear fluid. The arteries were quite natural. The lungs were very cedematous and emphysematous along their free margins; the heart was semi-contracted and empty; the marrin of the tricnspid value was very slightly thickened, but otherwise the organ was yuice natural. The liver was slightly congested; the spleen smal and pulpy; the kidneys were full of black blood, the surface was granular, and there was slight diminution in the amount of the secreting structure.

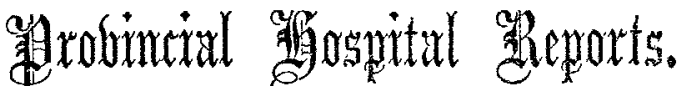

\section{GENERAL HOSPITAL NEAR NOTTINGHAM.}

GANGRENE OF THE KNEE, OPENING THE JOINT; DEATH,

(Under the care of Mr. Thompsox).

WE are indebted to Mr. Thompson, junior, for notes of this case.

James G-, aged seventy-eight, a blacksmith, was admitted into the hospital on the 2nd of January, 1867. Patient states that he has always enjoyed remarkably good health until the beginning of last October, when he first noticed that his left knee felt numb and dead; there was no redness at this time, but he was unable to walk, because of pain. He says that his left foot and leg always felt cold. In November the joint became swollen, red, and very painful; and about the 10th of December, he observed a small black spot on the onter side of the knee-cap, which gradually spread, and formed a complete circle round the patella, the skin covering the patella itself being quite natural in its appearance. He never received any injury to the part, although, from the nature of his employment, he may have done so unknowingly.

Present state. - To all appearance he is a healthy-looking man for his age : arcus senilis well marked; there is rigidity of his arteries, which may be seen beating at the bend of elbows and wrists, and feel hard, and roll from under finger; pulse 76 , rather weak and intermittent; heart-sounds feeble; no murmurs heard; appetite good; sleeps tolerably; the left thigh is warm; some fulness in the groin; the foot and ler feel cold, but he says they do not feel numb. Over the knee is a large slough, 6 by 5 inches in diameter; black at its outer edges, where it is separating from the sound skin, bat of a purplish green colour in the centre. The $\operatorname{limb}$ was in a bent position, and he cannot bear it to be put straight. The foot and leg were enveloped in cotton wool, a bread poultico applied to the knee, and patient ordered to take a inixture with ammonia, chloric ether, and cascarilla.

Jan. 18th. - The slough continues to separate; the central portion over the patella being now quite dead and black. To continue treatment.

23rd.-To-day, on a portion of the slough being removed, the joint was found to be quite open, tho inner condyle of the femur being quite exposed; a most offensive odour now comes from the wound. Two grains of quinine were ordered three times a day.

28th.-During the last three days he has had diarrhnea, slough continues to separate; does not complain of pain. To continue pill, and to have a chalk mixture and six ounces of wine. A small bedsore was discovered to-day on his right hip, of which he did not complain.

Feb. 3rd. - Is certainly not so well ; diarrhoea has ceased. Now complains of much pain in knee, which discharges a good quantity of very fetid pus; skin hot and dry ; pulse 140 tongue red and dry, brownish in centre. To repeat pill, and ammonia mixture, with brandy and eggs, \&c.

4th. - Is much exhausted ; takes very little nourishment on dressing the knee, a large blister, full of dark-greenish fluid, is seen on the back of the leg.

5 th. - The blister on the back of the leg has burst, and the skin beneath is black and discoloured. Patient is evidently sinking; pulse 144, weak and smali ; tongue dry and brown; skin cold and clammy.

6th. -Died at three A.M.

Autopsy eight hours after death.-Lungs congested, with slight inflammation of the bronchi. Heart soft, pale, flabby, and covered with fat; chambers of the heart dilated; ossific deposits were seen on the aortic and mitral valves. Atheromatous deposits in the coats of the aorta, and more especially abundant where branches were given off. The aorta at its bifurcation was quite brittle, and cracked beneath the finger.

Remarks.--The case presents two points of interest:1st. The fact that the knee should have heen the seat of this 